Www.jmscr.igmpublication.org

Index Copernicus Value: 79.54

ISSN (e)-2347-176x ISSN (p) 2455-0450

crossref DOI: https://dx.doi.org/10.18535/jmscr/v7i6.01

Journal Of Medical Science And Clinical Research

IGM Publication

An Official Publication of IGM Publication

\title{
A Clinical Study to Evaluate the Incidence of Ocular Manifestations in Patients with Nutritional Anemia
}

\author{
Authors \\ Dr Shazia Qayum ${ }^{1 *}$, Dr Kunal Sharma ${ }^{2}$ \\ ${ }^{1}$ MS Ophthalmology DNB Ophthalmology, Assistant Professor, GMC \& AH, Rajouri, J \& K \\ ${ }^{2}$ Resident Mmimsr, Mullana, Ambala \\ *Corresponding Author \\ Dr Shazia Qayum \\ MS Ophthalmology DNB Ophthalmology, Assistant Professor, GMC \& AH, Rajouri, J \& K
}

\begin{abstract}
Introduction: Anemia is a frequent haematological ailment presenting with diverse ophthalmic manifestations. It can involve any part of the eye and adnexa but principal features are conjunctival pallor and retinal haemorrhages retinal arteriolar and venous tortuosity, cotton wool spots, roth's spots, macular star and papilledema. This study evaluates the incidence of ocular manifestations in anaemia, relation between incidence of retinal haemorrhages with degree of severity of anaemia and prerequisite for fundus examination in all patients with anemia.

Objective: To evaluate the incidence of ocular manifestation in anemia and to evaluate correlation between the incidence of retinal haemorrhages and degree of severity of anemia.

Methodology: This prospective observational study was done in the department of Ophthalmology at GMC Rajouri from January 2019 - April 2019. A total of 96 patients, age group 18-50 years, diagnosed with nutritional anemia were included in our study after gaining written informed consent. Comprehensive haematological work up was done to exclude patients with anaemia other than nutritional cause. Evaluation of anterior segment of eye was done by slit lamp bio microscope. Evaluation of posterior segment of eye was done the help of direct/indirect ophthalmoscope/slit lamp biomicroscopy with $+90 D$ lens after full dilatation of pupil with Tropicamide eye drops.

Results: Out of total 96 patients with nutritional anaemia iron deficiency was seen in 52(54.16\%) patients, megaloblastic anaemia was seen in 16(16.66\%) patients and dimorphic anaemia was seen in $28(29.16 \%)$ patients. In our study we found that conjunctival pallor was the commonest ocular manifestation in anaemia and was present in all the cases. Patients with severe anaemia showed retinal haemorrhages in 26 (68.4\%) patients. In our study incidence and severity of retinopathy was higher with higher grades of anaemia.

Conclusion: Conjunctival pallor and flame shaped haemorrhages are most common ocular manifestations in patients with nutritional anaemia. Presence of conjunctival pallor needs evaluation for anaemia. Incidence and severity of retinal manifestations depends upon severity of anaemia.
\end{abstract}

Keywords: Anemia, Iron deficiency anemia, Conjunctival pallor, retinal haemorrhages.

\section{Introduction}

Anemia is a frequent haematological ailment presenting with diverse ophthalmic manifestations ${ }^{1}$. It can involve any part of the eye and adnexa but principal features are conjunctival pallor and retinal haemorrhages ${ }^{2}$ retinal arteriolar 
and venous tortuosity, cotton wool spots, roth's spots, macular star and papilledema. The severity of anaemia is related with severity of above mentioned signs. Substrate required for metabolism of retina is decreased in anaemia predisposing to hypoxic injury ${ }^{3}$. The anemic finding can be therefore be taken as indicator for retinal damage presenting as haemorrhage and pallor. ${ }^{4,5}$ This study evaluates the incidence of ocular manifestations in anaemia, relation between incidence of retinal haemorrhages with degree of severity of anaemia and prerequisite for fundus examination in all patients with anemia.

\section{Methodology}

This prospective observational study was done in the department of Ophthalmology at GMC Rajouri from January 2019 - April 2019. A total of 96 patients, age group 18-50 years, diagnosed with nutritional anemia were included in our study after gaining written informed consent.

Comprehensive haematological work up was done to exclude patients with anaemia other than nutritional cause. Patients with history of diabetes, hypertension, anaemia other than nutritional causes and media opacities were excluded. Detailed ocular examination of all the patients was done. Visual acuity was recorded in both eyes with a standard Snellen's chart. Evaluation of anterior segment of eye was done by slit lamp bio microscope. Evaluation of posterior segment of eye was done the help of direct/indirect ophthalmoscope/slit lamp biomicroscopy with +90D lens after full dilatation of pupil with Tropicamide eye drops. The details of the patients, type and severity of anaemia along with ocular manifestations consistent with anaemia were recorded. Data were analysed by using Chi-square test. The $\mathrm{p}$-value of $<0.05$ was taken as statistically significant.

\section{Results}

Out of total 96 patients with nutritional anaemia iron deficiency was seen in 52(54.16\%) patients, megaloblastic anaemia was seen in $16(16.66 \%)$ patients and dimorphic anaemia was seen in $28(29.16 \%)$ patients. In our study we found that conjunctival pallor was the commonest ocular manifestation in anaemia and was present in all the cases. Diminution of vision was noticed in 8 out of 16 patients $(50 \%)$ of megaloblastic anaemia and 18 out of $28(64.28 \%)$ patients of dimorphic anaemia. Patients with iron deficiency anaemia did not show any visual impairment. Lid edema was observed in 07out of $52(13.46 \%)$ patients with iron deficiency anaemia and 01 patient of dimorphic anaemia. Subconjunctival haemorrhage was seen in 01 out of $16(6.25 \%)$ patients of megaloblastic anaemia and 01 patient with iron deficiency anemia (1.9\%) and 4 out of 28 (14.28\%) patients of dimorphic anaemia. In our study, there was correlation between retinal haemorrhages and haemoglobin level in anaemic patients. Patients with mild-moderate anaemia showed retinal haemorrhages in $10(18.5 \%)$ patients. Table no.1 depicts the various ocular manifestations of anemia. Patients with severe anaemia showed retinal haemorrhages in 26 $(68.4 \%)$ patients. In our study incidence and severity of retinopathy was higher with higher grades of anaemia (Table no.2). The association between anaemia and retinal haemorrhage was statistically significant.

Table No.1 Distribution of Ocular Manifestations

\begin{tabular}{|l|c|c|c|c|}
\hline Ocular findings & $\begin{array}{c}\text { Iron deficiency } \\
\text { anemia }(\mathrm{n}=52)\end{array}$ & $\begin{array}{c}\text { Megaloblastic } \\
\text { anemia(n=16) }\end{array}$ & $\begin{array}{c}\text { Dimorphic } \\
\text { anemia }(\mathrm{n}=28)\end{array}$ & $\begin{array}{c}\text { Total } \\
(96 \text { cases })\end{array}$ \\
\hline 1.Diminution of Vision & nil & 08 & 18 & $26(27.1 \%)$ \\
\hline 2. Conjunctival pallor & 52 & 16 & 28 & $96(100 \%)$ \\
\hline 3.Subconjunctival haemorrhage & 01 & 01 & 04 & $06(6.2 \%)$ \\
\hline 4. Lid oedema shaped & 07 & Nil & 01 & $08(8.3 \%)$ \\
\hline $\begin{array}{l}\text { 5.Superficial flame } \\
\text { retinal haemorrhage }\end{array}$ & 06 & 20 & $36(37.5 \%)$ \\
\hline
\end{tabular}




\begin{tabular}{|l|c|c|c|c|}
\hline 6. Deep retinal haemorrhages & 04 & 10 & 16 & $30(31.2 \%)$ \\
\hline 7. Fundus pallor & 08 & 10 & 12 & $30(31.2 \%)$ \\
\hline 8.Roth's spots & 03 & 05 & 10 & $18(18.6 \%)$ \\
\hline 9. Dilated and tortuous veins & 01 & 02 & 01 & $04(4.2 \%)$ \\
\hline 10.Papilloedema & & 01 & 03 & $04(4.2 \%)$ \\
\hline 11. Subhyloid haemorrhage & 02 & 03 & 03 & $08(8.3 \%)$ \\
\hline 12 cotton wool spots & 02 & 02 & 04 & $08(8.3 \%)$ \\
\hline 13.Macular star & \multicolumn{4}{|l}{} \\
\hline
\end{tabular}

Table No.2 Relationship between Severity of Anemia and Retinal Haemorrhages

\begin{tabular}{|l|c|c|}
\hline $\begin{array}{l}\text { Haemoglobin in gm\% } \\
\text { (severity of anemia) }\end{array}$ & $\begin{array}{c}\text { No. of patients of } \\
\text { anemia presenting } \\
\text { with retinal } \\
\text { haemorrhages }\end{array}$ & \\
\hline $\begin{array}{l}7-10 \text { gm\% (mild to } \\
\text { moderate anemia) }\end{array}$ & $10(18.5 \%)$ & \multirow{2}{*}{0.03} \\
\cline { 1 - 2 } $\begin{array}{l}<7 \text { gm\% } \\
\text { (severe anemia) }\end{array}$ & $26(68.4 \%)$ & \\
\hline
\end{tabular}

$\mathrm{P}$ value $<0.05$ is considered statistically significant

Fundus pictures of patients with anemic retinopathy

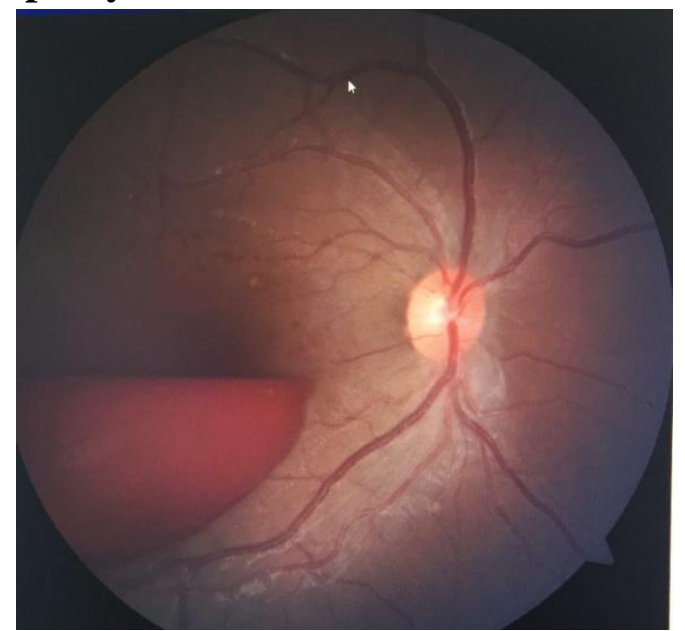

A) Subhyaloid Haemorrhage

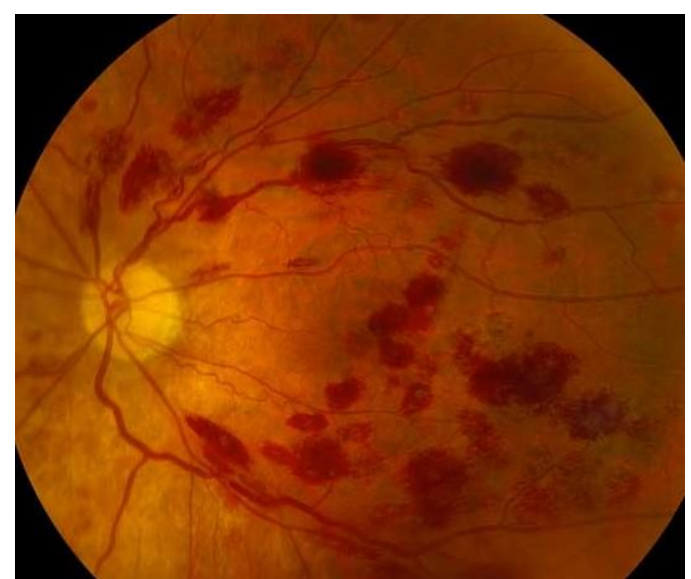

B) Superficial Haemorrhages With Tortuous Veins

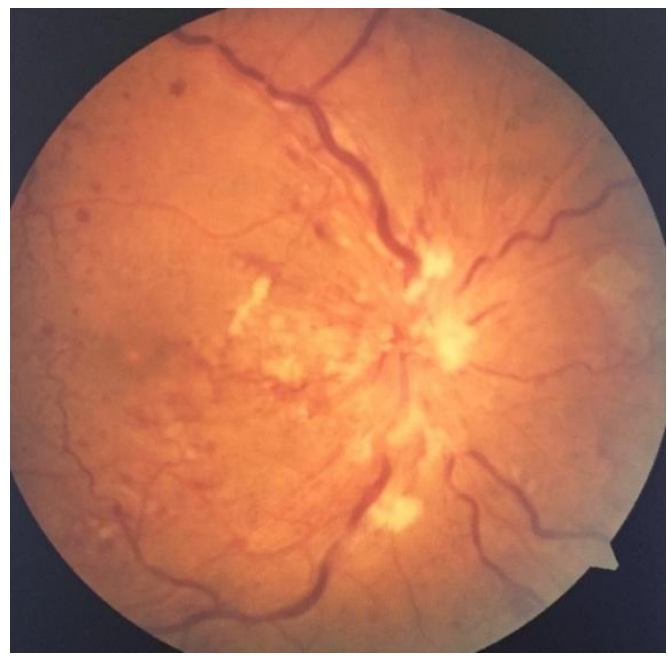

C) Patient With $\mathrm{Hb} \quad 4$ gm\% Showing Papilloedema, Tortuous Veins, Cotton Wool Spots, Superficial And Deep Haemorrhages.

\section{Discussion}

Ocular manifestations of anaemia have been progressively documented and anaemia due to multiple reasons may lead to diverse ocular manifestations ${ }^{1}$. Nutritional anaemia remains the commonest haematological anomaly in India. It can occur as a result of to deficiency of iron, folic acid or vitamin B12 with iron deficiency anaemia being the commonest form of nutritional anaemia. Maximum number of patients with ocular manifestation presents with symptoms necessitating an ophthalmic consultation. Amongst 96 patients in our study, maximum patients were of iron deficiency anaemia, visualloss most commonly noted with megaloblastic anaemia and dimorphic anaemia. However, in a study conducted by Anusha V et al described a rapid nonprogressive loss of vision due to iron deficiency anaemic retinopathy and megaloblastic anaemia with ophthalmic manifestations in the form flame shaped 
haemorrhage bilaterally, Roth's spot , cotton wool spots and sub hyloid haemorrhages. Probable factors causing retinal injury in anemia might include anoxia, increased capillary permeability, venous stasis and angiospasm ${ }^{6}$. In a study by Lang GE et al described that manifestations of anemiaare infrequent adnexal structure of eye. In our study we found the conjunctival pallor and retinal haemorrhages being the most common finding in anaemic patients. This result was comparable to the study done by Lang et al and Nusrat et $\mathrm{al}^{2,7}$ who concluded in their study that conjunctival pallor and retinal haemorrhages were commonest in ocular features in anemic patients. Existence of conjunctival pallor without additional evidence suggesting anaemia must be a reason sufficient enough to do haemoglobin estimation ${ }^{8}$. Retinal haemorrhages in both eyes are reported in patients with megaloblastic anaemia ${ }^{9,10}$. Superficial flame shaped haemorrhages were more common in our study followed by deep haemorrhage, white centred haemorrhages (roth's spots) and sub hyaloid haemorrhage. Holt JM et al considered 63 patients of anaemia and found that superficial flame shaped haemorrhages were commonest type of haemorrhage 11. Kalpana Suresh in her study of 34 patients with anaemia reported the flame shaped haemorrhages remained common trailed by deep haemorrhage ${ }^{3}$. Various studies also observed that tendency of retinal haemorrhages is higher if anaemia is associated with thrombocytopenia ${ }^{2,9,10,11}$. Pallor of the fundus was the another most common retinal manifestations in our study. Other retinal manifestations like venous and arteriolar dilatation, retinal edema, macular star etc were least common findings. Our study reported incidence of retinal haemorrhages was directly correlated with the magnitude of severity of anaemia which was statistically significant. Nusrat et al also stated that the retinal abnormalities were more common in severe anaemia $(34.2 \%)$ than in moderate anaemia $(7.5 \%){ }^{2}$ Merin S \& Freund have reported that the retinal abnormalities were found in $31.8 \%$ in patients with severe anemia while in moderate cases these were noted in on $13.3 \%$ of patients ${ }^{13}$. Ajit et al also observed that severity of retinal manifestations of anaemia was related to the severity of anaemia ${ }^{14}$.

\section{Conclusion}

Conjunctival pallor and flame shaped haemorrhages are most common ocular manifestations in patients with nutritional anaemia. Presence of conjunctival pallor needs evaluation for anaemia. Incidence and severity of retinal manifestations depends upon severity of anaemia. Early diagnosis of retinal manifestation may aid in early institution of treatment and thus early resolution of retinal changes.

\section{References}

1. Duke -Elder S., Dobree J. H. "The blood disease". Disease of Retina; 1 x. System of Ophthalmology C.V. Mosby Co 1967, Chapter IV, 373-381.

2. Nusrat Shaheen, Junaid S. Wani, A.R. Nasti, M.I. Quadri: Ocular manifestations in anaemia - A clinical study. $\mathrm{J} \mathrm{K}$ Practioner. 2005 July-Sept; 12(3): 128130.

3. Kalpana Suresh, Ramya sampath, Tanvi: Ocular manifestations in haematological disorders. Shri Ramchandra Journal of Medicine. 2011 Jan- Jun; 4(1): 1-4.

4. Rosenthal AR. Ocular manifestation of leukemia. A review. Ophthalmology 1983;90: 899-905.

5. Sethi A, Ghose S, Gujral S, Jain P, kumar R. Childhood proptosis: invaluable but overlooked peripheral smear. Indian J Ophthalmol 2001;49: 121-3.

6. Anusha Venkataraman, Bijnya B Panda, Anupam Dey MD: Nutritional anemia as a cause of vision loss in developing countries: A case report. Kerala journal of ophthalmology. Dec 2013; 25 (4): 383384.

7. Lang GE, Spraul CW, Lang GK. : Ocular changes in primary hematologic disease. 
Klin Montsbl Augenheikd, 1998; 212(6); 419.

8. Tarang N Sheth, Nitin K Chaudhary: The relation of conjunctival pallor to presence of anaemia. Journal of general Internal Medicine. 1997 Feb; 12 (2); 102-106.

9. Marwaha RK, Singh S, Garewal G, Marwaha N, Walia BN, Kumar L. Bleeding manifestations inmegaloblastic anaemia. Indian J Pediatr 1989; 56:243-7.

10. Lam S, Lam BL. Bilateral retinal hemorrhages from megaloblastic anemia: case report and review ofliterature. Ann Ophthalmol 1992; 24:86-90.

11. Holt J.M., Gorden -Smith E.C. Retinal abnormalities in diseases of the blood. Brit. J. Ophthalmol,1963; 53; 145-159.

12. Rubenstein R.A., Yanoff M., Albert D M: Thrombocytopenia, anaemia and haemorrhage. Am. J. Ophtholmol; 1968; $65 ; 435-439$.

13. Merin S., Freund M. Retinopathy in severe anaemia. Am. J. Ophthalmol, 1968; 66(6) 1102-1106.

14. Ajit Babu Majji, Kapil Bhatia, and Annie Mathai: Spontaneous bilateral peripapillary, subhyaloid and vitreous haemorrhage with severe anaemia secondary to idiopathic thrombocytopenic purpura. Indian J Ophthalmol. 2010 MayJun; 58(3): 234-236. 